\title{
RESEARCH
}

\section{Assessment of a Mutation in the H5 Domain of Girk2 as a Candidate for the weaver Mutation}

\author{
A.E. Mjaatvedt, ${ }^{1,2}$ D.E. Cabin, ${ }^{2}$ S.E. Cole, L.J. Long, G.E. Breitwieser, \\ and R.H. Reeves ${ }^{3}$
}

Department of Physiology, Johns Hopkins University School of Medicine, Baltimore, Maryland 21205

\begin{abstract}
A mutation in the GIRK2 inwardly rectifying $\mathrm{K}^{+}$channel was mapped recently to the region of mouse chromosome 16 containing the $w v$ gene and shown to occur in mutant but not in wild-type mice. We demonstrate tight linkage of the Girk2 mutation to the wv phenotype and refine the localization of the weaver (wv) gene on recombinational and physical maps. This linkage between Girk2 and wv has existed since at least 1988 in descendants of the original mutation maintained in C57BL/6 animals. Girk2 is shown to be transcribed in brain before the first recognized manifestation of the wv phenotype and in cultures of granule cells (GCs) isolated from cerebellum at postnatal day 8. Wild-type GCs grown in this culture system display an important developmental property-the ability to extend neurites. However, no inwardly rectifying $\mathrm{K}^{+}$ current is detected in GCs cultured from either $w v / w v$ or $+I+$ cerebellum under a variety of conditions that activate related channels in other tissues. This suggests that if the Girk2 mutation is responsible for the wv phenotype, it does not act by altering these electrical properties of developing GCs.
\end{abstract}

The weaver $(w v)$ mutation in mice was first characterized in 1973 as a recessive mutation resulting in hypoplasia of the cerebellar internal granule layer (IGL) (Rakic and Sidman 1973). As a consequence, $w v / w v$ mice display severe ataxia. Heterozygous $(+/ w v)$ individuals are not ataxic, but develop a significantly smaller cerebellum than do control animals. The $w v$ gene maps to a region of mouse chromosome 16 (Chr 16) that is highly conserved with human chromosome 21 (HSA21), suggesting that its normal human homolog is at dosage imbalance in Down syndrome (DS) (Reeves et al. 1989). The human homolog of $w v$ may also be involved in some forms of Parkinson's disease, as $w v / w v$ mice display a deficit in the dopaminergic projection to the caudoputamen traced to degeneration of the tyrosine hydroxylase-positive cells of the substantia nigra beginning at postnatal day 7 (P7) (Schmidt et al. 1982). In addition to these central nervous system (CNS) anomalies, sperm in the $w v / w v$ testis

\footnotetext{
'Present address: Center for Medical and Structural Biology, Medical University of South Carolina, Charleston, South Carolina 29403-5848.

2These authors contributed equally to this study.

${ }^{3}$ Corresponding author.

E-MAIL rreeves@welchlink.welch.jhu.edu; FAX (410) 955 0461.
}

progress to the late spermatid stage, but mature sperm are never released (Harrison and RofflerTarlov 1993).

The best-characterized aspect of the wv phenotype is the ataxia that results from a failure of granule cells (GC) to mature and migrate to form the cerebellar IGL. $w v / w v$ individuals are first identifiable at the day of birth (PO) by an increased number of pyknotic nuclei in the external granule layer (EGL) of the cerebellum (Smeyne and Goldowitz 1989). By 8 days of age, both the lack of GC migration in mutant animals and differences in cerebellar size and organization among $+/+, w v /+$, and $w v / w v$ mice are evident on histological analysis. Two distinct lines of investigation suggest that the $w v$ defect is GC specific, but give rise to conflicting conclusions about whether the defect is extrinsic or intrinsic. Aggregate cultures of neurons (presumptive GC) cultured from the EGL of young normal mice extend neurites, whereas $w v / w v$ aggregates do not. $w v / w v$ cells will extend neurites when aggregated with normal cells, or when exposed to a crude $+/+$ membrane extract, suggesting that wv GC lack a factor that is essential to normal development and that can be supplied extrinsically by $+/+$ cells (Gao et al. 1992). However, when chimeras are formed between $+/+$ and $w v / w v$ em- 


\section{MJAATVEDI ET AL.}

bryos, $w v / w v$ GC are never found in the IGL. This suggests that, in vivo, adjacent $+/+$ cells do not complement the mutation but rather that the defect is intrinsic to these cells (Goldowitz and Mullen 1982; Goldowitz 1989).

The $w v$ gene has been localized between $\mathrm{Cbr}$ and Pcp4, an interval amenable to positional cloning efforts (Mjaatvedt et al. 1993). Isolation of genes from the corresponding region of HSA21 and assessment of their murine counterparts led to the identification of a point mutation in the gene encoding the $G$ protein-coupled, inwardly rectifying $\mathrm{K}^{+}$channel, GIRK2 (Peterson et al. 1994; Patil et al. 1995). The Girk2 gene maps to the region of Chr 16 that contains the $w v$ gene, and the point mutation occurs in mutant but not wild-type animals, altering a highly conserved amino acid residue in the pore-forming region of the channel. A previous in situ hybridization study of GIRK2 in adult mice demonstrated distinct signals in the IGL of the cerebellum and in substantia nigra, the two brain areas known to be affected by the $w v$ mutation, and in hippocampus, pontine nuclei, olfactory bulb, cerebral cortex, septum, and amygdala (Kobayashi et al. 1995). GIRK2 mRNA is detectable by RNase protection from day $\mathrm{P} 1$ in mouse cerebellum and in testis but not liver, kidney, lung, spleen, or heart of adult mouse (Patil et al. 1995).

GIRK2 is a member of the recently identified superfamily of inwardly rectifying $\mathrm{K}^{+}$channels (see Doupnik et al. 1995). Activation of this class of channels can be achieved by exposure of the cell to agonists for receptors that couple to pertussis toxin-sensitive $G$ proteins, by direct persistent activation of the $G$ proteins themselves through intracellular application of GTP $\gamma$, or by direct application of activated $G$ protein subunits to excised membrane patches (Breitwieser 1991; Kurachi 1995). Pertussis toxin-sensitive G proteins are present in cerebellar $\mathrm{GC}$ as evidenced by the $\mathrm{GABA}_{\mathrm{B}}$ receptor-mediated inhibition of $\mathrm{Ca}^{2+}$ currents (Haws et al. 1993; Mintz and Bean 1993), and therefore, signaling pathways for activation of GIRK2 exist in these cells. G protein-activated inwardly rectifying $\mathrm{K}^{+}$channels serve, in many cell types, to reduce excitability in a receptorregulated manner, increasing membrane permeability to $\mathrm{K}^{+}$, and thus contributing to cell hyperpolarization. The Gly $\rightarrow$ Ser mutation within the H5 domain of Girk2 in wv mice might affect excitotoxicity, which could be related to degeneration of neurons in the substantia nigra (Goldowitz and Smeyne 1995; Patil et al. 1995), but would not easily account for the cerebellar phenotype as GC are not coupled electrically at the time the wv mutation exerts its effects. Patil et al. (1995) suggest that membrane hyperpolarization mediated by the GIRK2 channel may play an important role in normal GC development and that this is disrupted by the mutation.

To evaluate further Girk2 as a candidate for $w v$, it was mapped relative to the wv cerebellar phenotype, demonstrating tight linkage between them. The gene was localized on a yeast artificial chromosome (YAC)-based physical map of the region and oriented with respect to the chromosome. Girk 2 transcript was present by embryonic day 14 (E14), substantially earlier than the first known manifestations of the phenotype, and was readily detectable in cerebellum at $\mathrm{PO}$ and later. Cultures of purified EGL neurons from 8-day-old mice contained Girk2 mRNA. However, no inwardly rectifying $\mathrm{K}^{+}$current was detected in these presumptive GCs, and no differences in $\mathrm{K}^{+}$currents were detected between $+/+$ and $w v / w v$ cells under a variety of conditions. Our results refine genetic arguments for the candidacy of the Girk2 mutation as the basis for weaver, but suggest that the cerebellar phenotype does not arise from differences in inwardly rectifying $\mathrm{K}^{+}$currents between $+/+$ and $w v / w v$ GCs.

\section{RESULTS}

Previously, we reported the positions of 11 genes mapped on a high-resolution backcross panel in the region of distal Chr 16 that is homologous to HSA21, and localized $w v$ between Cbr and Pcp4 on 104 meioses of an intersubspecific backcross (Reeves et al. 1989; Mjaatvedt et al. 1993). This panel was typed with simple sequence repeat (SSR) markers D16Mit52 and Mit71 (Fig. 1). Two crossovers between Mit52 and $\mathrm{Cbr}$ demonstrated that the SSR maps $0.34 \mathrm{cM}$ proximal to $\mathrm{Cbr}(2 /$ 588). Mit71 did not recombine with Pcp4 on 554 meioses and thus is distal to $w v$.

To refine the location of the $w v$ locus, 124 progeny (248 meioses) were generated from an intercross between $F_{1}$ mice that were obligate heterozygotes at the $w v$ locus, [B6CBACa- $A^{\mathrm{w}-\mathrm{J}} / \mathrm{A}$ $w v \times \mathrm{MOLD} / \mathrm{Rk}] \mathrm{F}_{1}$. DNAs from these animals were analyzed with primers for Mit52 and Mit71, identifying 12 crossovers. Subsequent recombinational mapping of $w v$ was accomplished using these 12 DNAs representing the informative meioses from among 248 generated in the intercross, plus informative DNAs from among 104 progeny 
GIRk2 AS A w CANDIDATE GENE

CEN

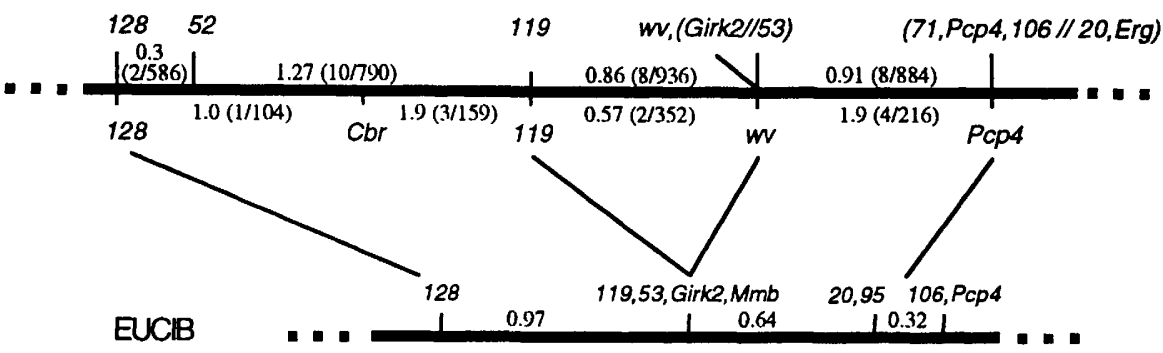

Figure 1 Recombinational map of the $w v$ region of Chr16 (top). Recombination fractions are shown in each interval for all crosses (above the chromosome) and for the w crosses (below the chromosome). No recombination was seen between wV, Girk2, and Mit53, nor between Mit71, Mit1 06, Mit20, Pcp4, and Erg. However, physical mapping data divides and orients each of these clusters as indicated by $/ /$. Orientation relative to the Chr 16 centromere (CEN) and the position of $\mathrm{Cbr}$ are shown. The EUCIB map (drawn to the same scale) (bottom) with the positions of Girk2, Mmb, and PCp4 (Patil et al. 1995) is included for comparison.

of the previously characterized backcross. The map was refined using DNAs from 490-584 progeny of three additional intersubspecific backcrosses (Table 1). This panel was typed to generate the map, Mit52-Cbr-119-wv, Mit53-Mit71 (Fig. 1). No recombination was seen between $w v$ and Mit53 on the mapping panel.

Primers specific for Girk2 (Table 2) were developed based on human and mouse Girk2 sequences (Lesage 1994; Kobayashi 1995; Tsaur 1995). The GIRK2-TM primer set amplified a 263bp product within the exon that encodes the M2 putative membrane-spanning domain and H5 pore-forming region and includes the base mutated in wv mice (Patil et al. 1995). The forward primer of this set recognizes a region that is divergent between known members of this subfamily of inwardly rectifying $\mathrm{K}^{+}$channels (Lesage et al. 1994; Doupnik et al. 1995). DNAs from seven animals known to be $+/+,+/ w v$, or $w v / w v$ were assessed by sequencing to validate this assay for detection of the mutation (Fig. 2). Twelve backcross and intercross progeny including all informative crossovers in the vicinity of $w v$ were evaluated to determine the parental type of the Girk2 locus. In each case, the Girk2 type was the same as $w v$ (i.e., no recombination was seen between the mutation and the phenotype on the informative DNAs from a total of 352 meioses). DNAs prepared in 1988 from $\mathrm{a}+/ w v$ and a $w v /$ $w v$ mouse that carried the $w v$ allele on the original C57BL/6-derived strain (Rakic and Sidman 1973; Reeves et al. 1989), also showed the expected type at the Girk2 locus. Analysis of these animals was repeated using single-strand conformation polymorphism analysis (SSCP) (Fig. 2) and extended to type an additional 16 animals ( 32 alleles) of known $w v$ phenotype for the mutant Girk2 allele, detecting no recombination. Twenty-three additional $+/+$ mice from a variety of strains were tested, including $\mathrm{A}, \mathrm{CBA}$, and $\mathrm{C} 57 \mathrm{BL} / 6$; the $w v$ mutation arose on $\mathrm{C} 57 \mathrm{BL} / 6$, and is maintained on a [CBA $\times \mathrm{A}^{-} \mathrm{F}_{1}$ hybrid background at the Jackson Laboratory, the main supplier of wv mice. None of these animals showed variation at the Girk2 locus.

Five mouse-derived YACs were identified with the GIRK-TM primers. All were positive for Mit53. Two were analyzed in detail to prepare a physical map of the region (Fig. 3). Nested deletion derivatives were prepared from YACs I6B12 and I90E3 using centric and acentric B1-targeted fragmentation vectors, respectively. Parental YACs and derivatives were analyzed for Mit53,

Table 1. Crosses Used in This Study-Female Parent is Indicated First in the Backcrosses

Cross Reference

$\mathrm{BALB} / \mathrm{C}) \times(\mathrm{BALB} / \mathrm{C}) \times \mathrm{MOLD} / \mathrm{Rk}) \mathrm{F}_{1}$

$\left.(B A L B / C) \times M O L D / R k) F_{1} \times B A L B / C\right)$

$(\mathrm{MOLD} / \mathrm{Rk} \times \mathrm{DW} / \mathrm{J}) \mathrm{F}_{1} \times \mathrm{DW} / \mathrm{J}$

$\mathrm{C} 57 \mathrm{BL} / 6 \mathrm{wv} / \mathrm{wv} \times(\mathrm{MOLD} / \mathrm{Rk} \times \mathrm{C} 57 \mathrm{BL} / 6 \mathrm{wv} / \mathrm{wv})$

Intercross between (B6CBACa-A $\left.{ }^{w-1} / \mathrm{A}-w v \times \mathrm{MOLD} / \mathrm{Rk}\right) \mathrm{F}_{1}$ mice
(Reeves et al. 1990, 1991)

(Reeves et al. 1990, 1991)

(Camper et al. 1990)

(Reeves et al. 1989; Mjaatvedt et al. 1993) (this study) 
MJAATVEDT ET AL.

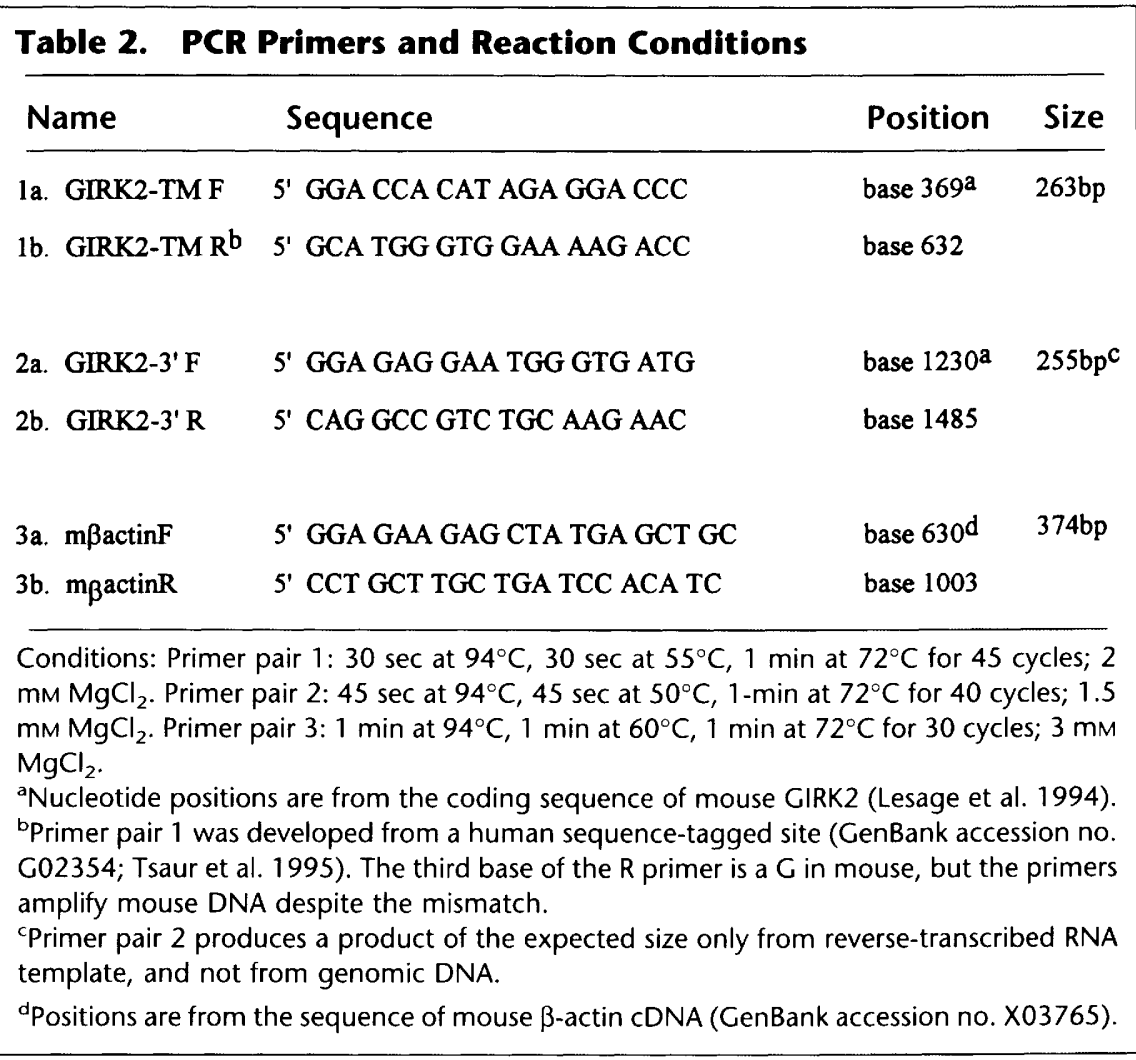

These subdivide the cluster into a $130-\mathrm{kb}$ segment containing pA33 and GIRK2-3', which is separated by $10 \mathrm{~kb}$ from an 80-kb segment delimiting GIRK2-TM and Mit53. YAC I90E3 overlaps at its centric end with YACs in a contig that extends proximally beyond $\mathrm{Cbr}$ (D. Cabin, J. McKee-Johnson, $M$. Citron, and R. Reeves, in prep.) and thus, the Girk2 gene is oriented on Chr 16 with the 3' end closest to the centromere. The physical map confirms the order $\mathrm{Cbr} \rightarrow 119 \rightarrow$ Girk2 determined on the recombinational mapping panel.

\section{Temporal Pattern of Girk2 Expression}

The Girk2-3' primers amplify the expected 255-bp product from cDNA and do the GIRK2-TM and GIRK2-3' PCR products, and pA33, the acentric end-clone of a third Girk2positive YAC, 182A2. A $105-\mathrm{kb}$ and a $115-\mathrm{kb}$ derivative of YAC I90E3 lacked all four markers, whereas all were retained on a $310-\mathrm{kb}$ derivative, placing them within $195 \mathrm{~kb}$ of each other. Figure 3 shows four fragmentation derivatives of I6B12.

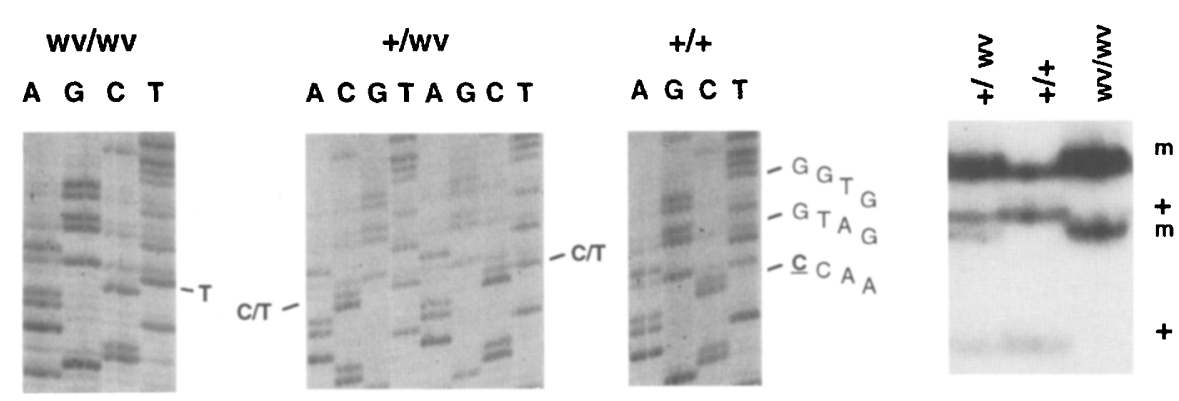

Figure 2 Detection of the Girk2 mutation at position 466 by sequencing and SSCP. Results of sequencing products from $w v / w v,+/ w v$, and $+/+$ animals are shown. Using the GIRK2-TMR oligonucleotide as a sequencing primer, the wildtype sequence is $C$ at position 466, and the mutant allele is T (Patil et al. 1995). The last panel shows an SSCP analysis of $+/ w v,+/+$, and $w v / w v$ mice. A " + " indicates bands corresponding to the wild-type allele (i.e., a $C$ at position 466) and " $m$ " indicates bands specific to animals with the Girk2 mutation ( $T$ at position 466). A nonspecific band appears in all lanes just below the highest mutant specific band. not amplify genomic DNA. These primers were used to analyze Girk2 transcripts in brain from E10 through P30 by RT-PCR (Fig. 4). Girk2 transcript is present in RNA extracts from whole brain by E14. Expression was readily detected in cerebellum at $\mathrm{P} 0$, the earliest point at which $w v / w v$ mice can be distinguished from nonmutant animals (Smeyne and Goldowitz 1989). Thus, the gene is transcribed in cerebellum at the time that the phenotype is detectable. Transcript was also detected in testis and pancreas as described previously (Lesage et al. 1994; Patil et al. 1995; Tsaur et al. 1995).

\section{Absence of Inwardly Rectifying $\mathrm{K}^{+}$Current in $+I+$ and $w v / w v$ Cultured Cerebellar Neurons}

Presumptive GC were isolated from the cerebellum of mice at P8 and assessed 
GrRk2 AS A w CANDIDATE GENE

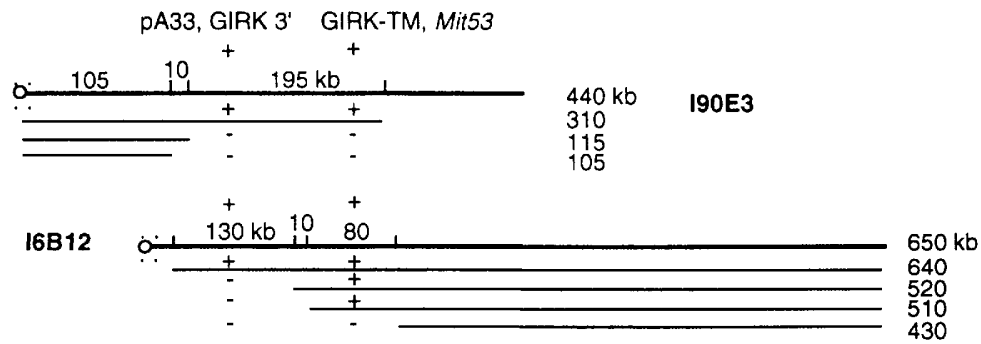

Figure 3 Fragmentation derivatives of Girk2-positive YACs 190E3 and 16B12 were typed to determine the orientation of pA33, Girk2, and Mit53. GIRK2-TM and GIRK2-3' refer to the presence of the PCR products corresponding to these primers (Table 2). The pres-

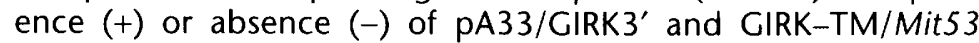
groups on each derivative are indicated. Sizes of the YACs and derivatives are in kilobases $(\mathrm{kb})$. The Chr 16 centromere is to the left (i.e., the same orientation as Fig. 1).

for structural and functional integrity (Gao and Hatten 1993). Identity of the cells was established by histochemical reactivity of $>95 \%$ of cells with tetanus toxin (not shown) and with antibody Q600, which is specific for GC (Gravel et al. 1987) (Fig. 5). Biological integrity of the cells was demonstrated by showing that aggregate cultures extend neurites (Fig. 5E). RT-PCR analysis of $+/+$ and $+/ w v$ cultures demonstrated the presence of Girk2 mRNA (Fig. 5F).

GCs were examined by the whole cell patch clamp technique. Outward $\mathrm{K}^{+}$currents were observed in $+/+$ GCs at potentials more positive than $-30 \mathrm{mV}$ and were comprised of a transient outward current $\left(\mathrm{I}_{\mathrm{A}}\right)$ and a delayed current $\left(\mathrm{I}_{\mathrm{K}}\right)$ as described previously for rat GCs (Jalonen et al. 1990; Galdzicki et al. 1991; Zegarra-Moran and Moran 1994). Analysis of GCs from $w v / w v$ mice yielded comparable results (Fig. 6B). The normalized, averaged current/voltage relationships for six $+/+$ and five $w v / w v$ GCs are illustrated in Figure 6C. $w v / w v$ GCs displayed a somewhat higher half-maximal activation voltage for the outward currents, which might represent slight differences in the relative expression of $I_{A}$ and $I_{K}$. However, the linear, inward currents were identical in $+/+$ and $w v / w v$ GCs. These inward currents extrapolate through $0 \mathrm{mV}$ and most likely represent contributions from both leak and $\mathrm{Cl}^{-}$currents.

Substitution of pipet $\mathrm{K}^{+}$with $\mathrm{N}$-methyl-Dglucamine (NMDG) abolished all outward currents, confirming that $\mathrm{K}^{+}$channels were responsible. No changes in currents were observed in response to $10 \mu \mathrm{M}$ of baclofen $(n=2), 10 \mu \mathrm{M}$ of dopamine $(n=3)$, or $10 \mu \mathrm{M}$ of acetylcholine $(n=3)$. Furthermore, no time-dependent changes in $\mathrm{K}^{+}$current were elicited by $1 \mathrm{~mm}$ pipet GTP $\gamma$ in 5 cells from $w v / w v$ and 10 cells from $+/ w v$ animals tested under similar conditions. The presence in these cells of functional, pertussis toxin-sensitive $G$ proteins was confirmed by GTP $\gamma$ Smediated decreases in inward currents in the presence of $50 \mathrm{~mm}$ extracellular $\mathrm{BaCl}_{2}$ (data not shown). Cells were monitored for GTP $\gamma$ S-mediated changes in current for an average of $15-30 \mathrm{~min}$, and several cells were monitored for $45 \mathrm{~min}$. No changes in outwardly rectifying $\mathrm{K}^{+}$ currents were observed, nor was there development of additional, inwardly rectifying currents. Control cells were also examined with a pipet solution containing 0 ATP, 0 GTP $(n=7)$, but no inward currents indicative of the presence of $\mathrm{K}_{\mathrm{ATP}}$ channels were elicited. In two experiments, $150 \mu \mathrm{M}$ pinacidil, which activates $\mathrm{K}_{\mathrm{ATP}}$ channels (Tseng and Hoffman 1990; Zegarra-Moran and Moran 1994), failed to affect cellular $\mathrm{K}^{+}$currents in GCs.

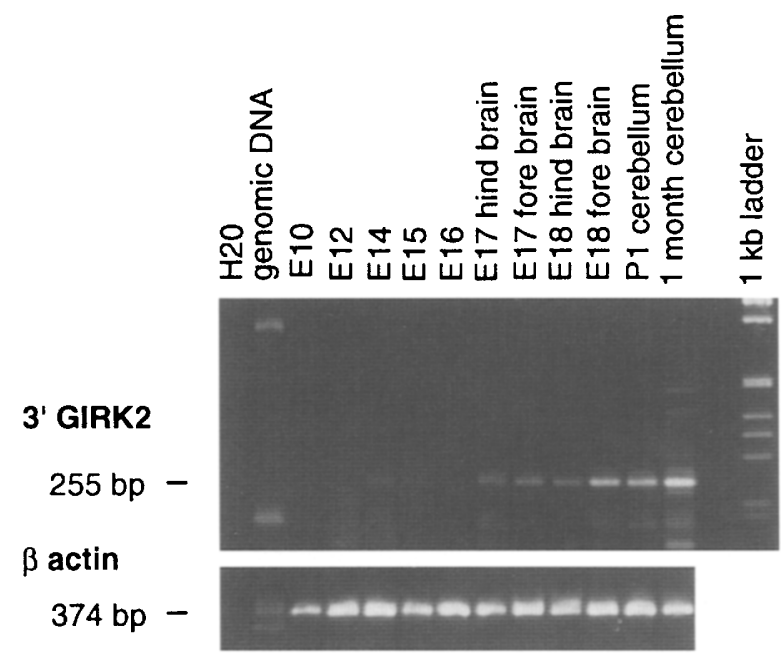

Figure 4 Developmental and tissue profile of Girk2 expression. Staged embryos were isolated from timed matings. RNA was isolated from whole head at E10, whole brain on E14-E16, from the anterior or posterior half of the brain at later prenatal time points, and from isolated cerebellum at P1 and P30. For all analyses, RT-PCR analysis was performed with the GIRK2-3' primers that identify a 255-bp product in CDNA but not genomic DNA using conditions described in Table 2. Amplification with $\beta$-actin was used as a positive control for the presence of CDNA. 
MJAATVEDT ET AL.

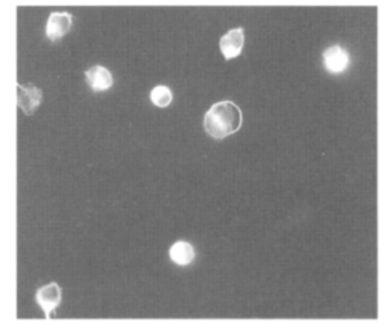

A

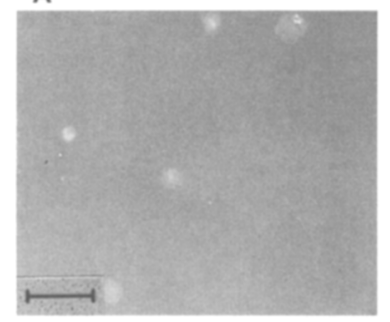

c

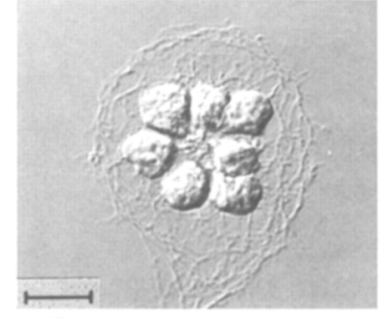

E

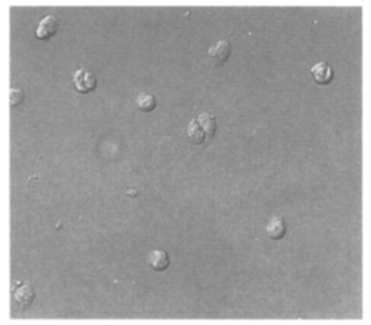

B

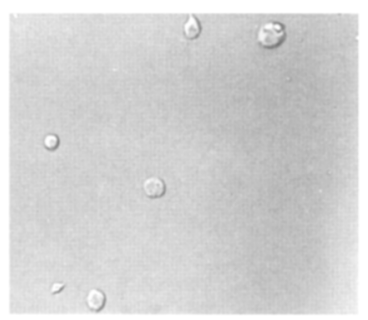

D

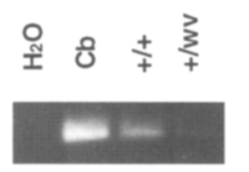

F

Figure 5 Cell type specificity and biological integrity of GC cultures. More than $95 \%$ of cells reacted with GC-specific Q600 antibody; cultures are pictured under fluorescence $(A)$ and phase $(B)$. Note presence of one Q600 negative cell. No staining was observed with secondary antibody alone viewed under fluorescence $(C$ and phase $(D)$. GC extend neurites when cultured as aggregates $(E$ ). Girk2 transcript was detected by RT-PCR with the GIRK2-3' primers in adult cerebellum and in GC cultures from $+/+$ and $+/ w v$ animals $(F)$. (A-D) Bar, $25 \mu \mathrm{m}$; (E) bar, $10 \mu \mathrm{m}$.

\section{DISCUSSION}

Several criteria must be met to determine whether a candidate gene is responsible for a specific mutation. First, the candidate should map to the correct chromosomal region and show no recombination with the mutant phenotype in a significant number of affected individuals (assuming complete penetrance). Second, the mutant allele should differ from wild type in structure and expression. Frequently, structural differences can be identified by analysis at the DNA or protein level. Changes in expression can be manifested in several ways. The mutation could result in different levels of expression (up or down),

alter the timing of expression during development, or change the cell or tissue distribution of transcription. Third, candidacy of a mutation can be strengthened by demonstration of a plausible mechanism by which the candidate mutation could produce the phenotype. Finally, direct proof of the role of the candidate gene is obtained by the demonstration of an independently occurring mutant allele that results in the same phenotype, by the demonstration that the mutant phenotype is complemented by a normal copy of the gene in transgenic mice, or by recapitulation of the mutation via gene replacement.

The Girk2 mutation meets several criteria as a candidate for $w v$. It was mapped initially between D16Mit128 and Pcp4 to the same locus as Mit53 and Mit119 in an interval of Chr 16 measuring $-1.9 \mathrm{cM}$ on an interspecific cross (Patil et al. 1995). This result does not formally restrict Girk2 to the previously defined $w v$ candidate region that is delimited proximally by $\mathrm{Cbr}$, as Mit128 is proximal to $\mathrm{Cbr}$. Interspecific maps are compressed in this region (Reeves et al. 1990). On the crosses segregating $w v$ in this study, the interval between Mit 128 and Pcp 4 was $5.4 \mathrm{cM}$ or $>5 \%$ of the recombinational map of $\mathrm{Chr} 16$, a region that might be expected to contain $>150$ candidate genes. The localization of both Girk 2 and $w v$ was refined using a high resolution mapping panel and YAC-based physical mapping. Mit119 was mapped $0.57 \mathrm{cM}$ proximal to $w v$ and Girk 2 on our high resolution panel, whereas physical mapping placed Mit53 distal to the 3' end of the gene, and $<80 \mathrm{~kb}$ from the transmembrane-encoding portion of Girk2. No recombination was seen between the $\mathrm{G} \rightarrow$ A mutation and the wv cerebellar phenotype on $>350$ chromosomes, providing a $95 \%$ probability that the genes are separated by $<0.8 \mathrm{cM}$. This segment will be delimited further as the remaining six crossovers between $w v$ and the closest flanking markers are positioned precisely.

GIRK2 mRNA is detectable in brain at E14, several days before the wv phenotype is evident, and is expressed in cerebellum throughout late embryonic and postnatal development. Message is detected in testis, as might be expected, as $w v$ / $w v$ males are known to have a defect in spermatogenesis. Expression also occurs in pancreas (Tsaur et al. 1995) and in multiple brain regions not known to be affected by the $w v$ mutation (Kobayashi et al. 1995). Ultimately, the role of this mutation should be considered at all sites where the gene is expressed. 


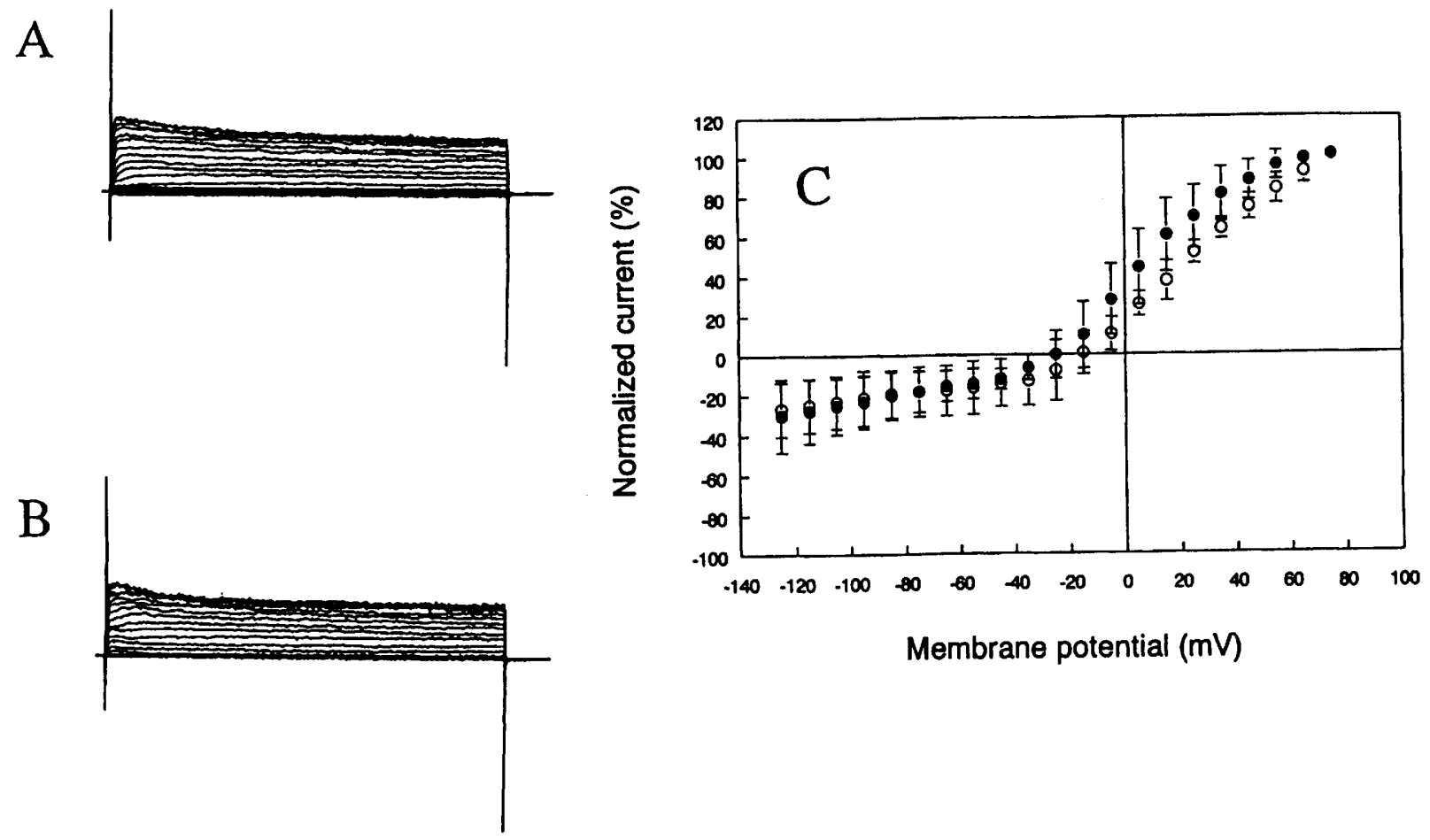

Figure 6 Electrophysiological characteristics of mouse cerebellar GC. Voltage clamp current responses from $+/+$ $(A)$ and $w v / w v(B) \mathrm{GC}$ held at $-85 \mathrm{mV}$ and stepped to potentials from $-125 \mathrm{mV}$ to $+105 \mathrm{mV}$ in 10 - $\mathrm{mV}$ increments, with a return to holding potential between voltage steps. Pipet solution contained 1 mM GTP $\gamma$. Traces were taken -15 min after patch rupture. Bars, 200 pA and $50 \mathrm{msec}$. (C) Steady-state currents (measured at $250 \mathrm{msec}$ after initiation of the pulse) were normalized to the steady-state current obtained at $+75 \mathrm{mV}$. Normalized currents were averaged for six $+/+$ and five $w v / w v$ GC and the current-voltage relationships plotted. Average steady-state currents at $+75 \mathrm{mV}$ were $98.5 \pm 39.4 \mathrm{pA}$ for $+/+$ and $84 \pm 35 \mathrm{pA}$ for $w v / w v$ cells. (e) $+/+\mathrm{GC} ;(0) w v / w v$ GC.

Neurons cultured from mouse cerebellum during the first 2 weeks after birth show many properties of GCs, including the ability to participate in migration and IGL formation when injected into the cerebellum of newborn mice (Gao et al. 1992; Gao and Hatten 1993). Electrophysiological properties of these presumptive GC precursors were examined to identify possible functional consequences of the Girk2 mutation. Our observations do not demonstrate the presence of inwardly rectifying $\mathrm{K}^{+}$channel currents in these cells under a variety of conditions that stimulate other members of this gene family. Neither baclofen nor dopamine elicits changes in net membrane currents in normal or mutant GCs. Furthermore, inclusion of $1 \mathrm{~mm}$ GTP $\gamma S$ in the pipet solution did not elicit activation of an inwardly rectifying $\mathrm{K}^{+}$current over 15 - to 30 -min periods (Fig. 6) $(n=17$ control; $n=16 w v / w v$ and $+/ w v)$, although persistent activation of pertussis toxinsensitive $G$ proteins in mouse cerebellar GCs is complete in $5 \mathrm{~min}$ upon exposure to $500 \mu \mathrm{M}$
GTPYS (Haws et al. 1993). In similar experiments in atrial myocytes, $1 \mathrm{~mm}$ pipet GTP $\gamma$ elicits maximal activation of muscarinic $\mathrm{K}^{+}$currents within 3-5 min (Breitwieser and Szabo 1988). The absence of inwardly rectifying $\mathrm{K}^{+}$channels in cultured mouse GCs 8 days after birth is consistent with previous observations of rat GCs (Jalonen et al. 1990; Galdzicki et al. 1991; Zegarra-Moran and Moran 1994).

Girk2 transcript was present in the GC cultures as determined by a robust signal using RTPCR (Fig. 5F). Thus, the Girk2 gene is transcribed in at least some cells in these cultures that are composed of $>95 \%$ GCs, but its expression does not result in the establishment of inwardly rectifying currents analogous to those in other cells. Although cerebellar development is distinctly affected in both $+/ w v$ and $w v / w v$ mice, no differences were seen in the electrophysiological properties of $+/+,+/ w v$, or $w v / w v$ GCs. The culture model used here contains the potential for isolation-induced alterations in GC properties, partic- 


\section{MJAATVEDT ET AL.}

ularly to the signal transduction pathways leading to GIRK2 activation. This problem is circumvented by applying GTP $\gamma S$ intracellularly to activate $G$ proteins directly, which are localized to the cytoplasmic face of the plasma membrane, thus bypassing extracellular receptors that could be affected by the cell isolation procedure. The muscarinic $\mathrm{K}^{+}$channel comprised of GIRK1 and CIR is resistant to extracellular collagenase, trypsin, and protease, which are used typically to dissociate myocytes acutely for same day recording (Tung and Morad 1985; Fischmeister and Hartzell 1986). As demonstrated in rat and mouse GC, a variety of signaling pathways that regulate $\mathrm{Ca}^{2+}$ channels are robustly present after isolation (Marchetti et al. 1991; Haws et al. 1993; Huston et al. 1993; Lambert and Feltz 1995), including those using pertussis toxin-sensitive $G$ proteins that also interact with Girk2. Recent results suggest that GIRK channels must heteromultimerize with other members of the subfamily to produce functional channels (Ferrer et al. 1995; Krapvinsky et al. 1995; Nichols et al. 1995), and thus, the presence of GIRK2 alone may not be sufficient to ensure functional channel expression. It remains to be seen whether GC cells express other members of the GIRK family during the postnatal time period under investigation in this study.

The $w v$ mutation arose in the inbred C57BL/6 strain in 1973 (Rakic and Sidman 1973). DNA isolated in 1988 from $w v / w v$ and $+/ w v$ descendants of the original line maintained on the B6 background carried the Girk2 point mutation, suggesting that it has been maintained with $w v$ for at least 20 generations. Given the tight linkage of Girk2 with $w v$, it would be expected to cosegregate in animals selected for inheritance of the $w v$ phenotype. Initial experiments to assess a possible functional role for the Gly $\rightarrow$ Ser mutation in GIRK2 function that might account for the cerebellar phenotype do not demonstrate inwardly rectifying $\mathrm{K}^{+}$currents in cultured $\mathrm{GC}$ from either $+/+$ or $w v / w v$ mice at P8.

The genetic evidence provided here strengthens the likelihood that the Girk2 mutation is responsible for the wv phenotype. The impact of this mutation on noncerebellar aspects of $w v$, (i.e., the spermatogenesis defect, seizures, and the presence or absence of a phenotype in tissues that express GIRK2 but are not known to be affected) remains to be assessed. The highresolution physical and recombinational mapping greatly delimit the possible location of $w v$ candidates and provide reagents for the creation of transgenic or gene replacement mice that should demonstrate directly whether the Girk2 mutation is responsible for the $w v$ phenotype.

\section{METHODS}

\section{Genetic Mapping}

Animals carrying the $w v$ mutation were obtained from the Jackson Laboratory, where they are maintained on an $\mathrm{F}_{1}$ hybrid genetic background, B6CBACa- $\mathrm{A}^{\mathrm{w}-\mathrm{J}} / \mathrm{A}-w v$. The four backcrosses used in this analysis have been described previously (Table 1). Additional meioses informative for $w v$ were generated in an intercross. Homozygous wv $(w v / w v)$ females were crossed to males of the inbred Mus musculus subsp. molossinus strain, MOLD/Rk, and an intercross established between their obligate $+/ w v$ progeny. One hundred twenty-four $F_{2}$ progeny were sacrificed between P6 and P21. Whole brains, liver, kidney, and spleen were immediately frozen in dry ice and stored at $-80^{\circ} \mathrm{C}$. DNA and RNA extraction, Southern blotting, radiolabeled probe synthesis, and hybridization were accomplished using standard procedures as described (O'Hara et al. 1988, 1989; Reeves et al. 1991). Clone pCR311 was used to detect an EcoRI restriction fragment length polymorphism (RFLP) at Cbr (Mjaatvedt et al. 1993). PCR primers for D16Mit markers were obtained from Research Genetics, Inc.; additional primers and reaction conditions used in all experiments are described in Table 2. PCR products were separated on $3.5 \%$ low melting point agarose gels and visualized under UV light after staining with ethidium bromide (Irving et al. 1993).

SSCP was carried out as described (Orita et al. 1989), using PCR products prepared with $\gamma^{3}{ }^{32} \mathrm{P}$-end-labeled GIRK2-TMF and/or GIRK2-TMR primers to the poreforming region of Girk2, which contains the G $\rightarrow$ A mutation at position 466 of coding sequence (Lesage et al. 1994) (Table 2). Products were denatured, then resolved on nondenaturing $6 \%$ acrylamide gels containing $5 \%$ or $10 \%$ glycerol run at $6 \mathrm{~W}$ for $14 \mathrm{hr}$ at room temperature. Amplified PCR products were sequenced with the Sequenase system (U.S. Biochemical) using the GIRK2-TMF primer ( 0 - to 1-min extension) and the GIRK2-TMR primer (2-min extension) and resolved on $6 \%$ acrylamide denaturing gels. Products from at least two independent PCR reactions of every DNA were sequenced in both directions.

The weaver genotype was assessed by histological examination of cerebella. Frozen brains were cut parasagitally and half of the brain was embedded in optimally controlled temperature (OCT) tissue freezing medium (Sigma Chemical) for cryostat sectioning. Midline parasagittal sections were cut at $10-\mu \mathrm{m}$ thickness and stained with cresyl violet using standard techniques. RT-PCR was performed on RNAs harvested from indicated tissues using Superscript reverse transcriptase according the manufacturer's instructions (Life Technologies, Inc.).

\section{Physical Mapping on YACs}

Mouse-derived YACs were identified by PCR-based screening of Research Genetics, Inc. pools of the Massachusetts Institute of Technology library and the Baylor School of 


\section{GIRk2 AS A wv CANDIDATE GENE}

Medicine pools of Imperial Cancer Research Foundation (ICRF) and St. Mary's libraries. Standard conditions were used for preparation of high molecular weight DNA in agarose plugs (Pavan et al. 1990). DNA for PCR and conventional Southern blot analysis was prepared by the method of Hoffman and Winston (1987). Physical mapping of markers on YACs was facilitated by YAC fragmentation (Pavan et al. 1990) using a centric YAC fragmentation vector pLM1 (L. Matesic and R. Reeves, in prep.) and an acentric vector, pJW522 (kindly provided by J. Edmundson, Rockefeller University, New York) that target homologous recombination to murid $B 1$ repetitive elements. Fragmented YACs were analyzed using PCR products of Girk2 and pA33 as hybridization probes.

\section{GC Preparation}

GCs were isolated as described (Huettner and Baughman 1986; Gao et al. 1992). Briefly, cerebella from P2 to P8 mice were dissected in calcium- and magnesium-free phosphate-buffered saline (CMF-PBS; GIBCO-BRL) to remove meninges. The remaining tissue was minced and placed in Earl's balanced salt solution (EBSS) containing $20 \mathrm{U} / \mathrm{ml}$ of papain and $0.005 \%$ DNase (Worthington Biochemical Corporation). The tissue was incubated at $37^{\circ} \mathrm{C}$ for $1 \mathrm{hr}$ then triturated and centrifuged at $70 \mathrm{~g}$ through a gradient of bovine serum albumin containing ovomucoid protease inhibitor. Cells were resuspended in CMF-PBS and viability was determined by trypan blue exclusion. The single cell suspension was applied onto a discontinuous gradient of $35 \%$ and $60 \%$ Percoll in CMF-PBS (Pharmacia) and subjected to centrifugation at $800 \mathrm{~g}$ for $10 \mathrm{~min}$. Cells were collected from the interface, washed in CMF-PBS, and suspended in $2 \mathrm{ml}$ of growth medium (Dulbecco's modified Eagle medium containing $10 \%$ horse serum, 5\% fetal calf serum, $4.5 \mathrm{~g} / 1$ of glucose, $50 \mathrm{U} / \mathrm{ml}$ of penicillin, $50 \mu \mathrm{g} / \mathrm{ml}$ of streptomycin). Cells were plated onto poly-D-lysine (25-50 $\mu \mathrm{g} / \mathrm{ml},>300,000$ m.w.; Sigma) coated 35-mm Petri dishes for $30 \mathrm{~min}$ at $37^{\circ} \mathrm{C}\left(5 \% \mathrm{CO}_{2}\right)$ allowing astrocytes to adhere. The plate was then swirled gently and unattached cells were collected. This panning procedure was repeated and unattached cells were washed and resuspended in growth medium. Monolayer cultures for electrophysiology and cell staining were established by plating cells on poly-Dlysine coated glass chips in a 24 -well dish at a density of $2 \times 10^{5} / \mathrm{ml}$ and incubating at $37^{\circ} \mathrm{C}$ for $24-48 \mathrm{hr}$ before use. For reaggregate cultures, $5 \times 10^{4}$ cells were plated into one well of a 96-well plate and incubated for $12 \mathrm{hr}$ at $37^{\circ} \mathrm{C}$, by which time most cells had formed small aggregates that were transferred onto poly-D-lysine-treated $12-\mathrm{mm}$ glass coverslips in a 24 -well dish and incubated further at $37^{\circ} \mathrm{C}$.

Purity of the cultures was assessed by antibody staining. GCs were fixed in $4 \%$ formaldehyde in PBS for $10 \mathrm{~min}$ at room temperature. For Q600 staining, cells were then washed and incubated overnight at $4^{\circ} \mathrm{C}$ with the Q600 antibody (a granule cell specific monoclonal antibody kindly provided by Dr. Richard Hawkes, University of Calgary, Canada) (Gravel et al. 1987). Cells were washed three times in PBS, then incubated with fluorescein isothiocyanate (FITC)-conjugated goat anti-mouse IgG $\mathrm{F}(\mathrm{ab})^{\prime} 2$ (10 $\mu \mathrm{g} / \mathrm{ml}$, Boehringer Mannheim) at $20^{\circ} \mathrm{C}$ for $1 \mathrm{hr}$. The coverslips were washed thoroughly and mounted in aqueous mounting medium. For anti-tetanus toxin fragment $C$ (TTC) staining the cells were preincubated with recombi- nant TTC fragment as described in the manufacturer's instructions, washed in PBS and incubated with anti-TTC monoclonal antibody (1:200; Boehringer Mannheim) for 1 hr at $20^{\circ} \mathrm{C}$. The remainder of the staining procedure was identical to that for Q600. Staining with secondary serum alone was used as a negative control.

\section{Electrophysiology}

Whole cell currents were recorded by standard high resolution patch clamp techniques as described previously (Scherer and Breitwieser 1990), with an LIST EPC-7 amplifier, filtered at $2 \mathrm{kHz}$ (8-pole Bessel filter) and stored on computer and/or VCR tape. Data acquisition and analysis was performed with Pclamp software (version 5.5.1; Axon Instruments). All experiments were performed at a holding potential of $-85 \mathrm{mV}$ and at $20^{\circ} \mathrm{C}-22^{\circ} \mathrm{C}$. The bath solution contained $150 \mathrm{mM} \mathrm{NaCl} ; 5 \mathrm{~mm} \mathrm{KCl} ; 2 \mathrm{~mm} \mathrm{MgCl} ; 2 \mathrm{~mm}$ $\mathrm{CaCl}_{2}$; and $10 \mathrm{~mm}$ HEPES ( $\mathrm{pH}$ 7.3). The pipet solution contained $160 \mathrm{mM} \mathrm{KCl} ; 2 \mathrm{~mm} \mathrm{MgCl} ; 2$ mM KEGTA; and $10 \mathrm{~mm}$ HEPES ( $\mathrm{pH} 7.2$ ). In certain experiments, the pipet solution was supplemented with $1 \mathrm{~mm}$ GTP $\gamma$ S (Li salt), $5 \mathrm{~mm}$ MgATP.

\section{ACKNOWLEDGMENTS}

We thank Michael Citron and David Patch for excellent technical assistance and Jenna McKee-Johnson and Lydia Matesic for fragmentation derivatives. Some YAC clones were obtained with the assistance of the Baylor University YAC screening core, C. Chinault, P.I. D.E.C. was supported in part by a March of Dimes Foundation predoctoral award, and L.J.L. was supported by a National Science Foundation predoctoral fellowship. This work was supported by U.S. Public Health Service awards HG00405 and HD24605 (RHR).

The publication costs of this article were defrayed in part by payment of page charges. This article must therefore be hereby marked "advertisement" in accordance with 18 USC section 1734 solely to indicate this fact.

\section{REFERENCES}

Breitwieser, G.E. 1991. G protein-mediated ion channel activation. Hypertension 17: 684-692.

Breitwieser, G.E. and G. Szabo. 1988. Mechanism of muscarinic receptor-induced $\mathrm{K}^{+}$channel activation as revealed by hydrolysis-resistant GTP analogues. J. Gen. Physiol. 91: 469-493.

Camper, S.A., T.L. Saunders, R.W. Katz, and R.H. Reeves. 1990. The Pit-1 transcription factor gene is a candidate for the murine Snell dwarf mutation. Genomics 8: $586-590$.

Doupnik, C.A., N. Davidson, and H.A. Lester. 1995. The inward rectifier potassium channel family. Curr. Opin. Neurobiol. 5: 268-277.

Ferrer, J., C.G. Nichols, E.M. Makhina, L. Salkoff, J. Bernstein, D. Gerhard, J. Wasson, S. Ramanandham, and 


\section{MJAATVEDT ET AL.}

A. Permutt. 1995. Pancreatic islet cells express a family of inwardly rectifying $\mathrm{K}^{+}$channel subunits which interact to form G-protein-activated channels. J. Biol. Chem. 270: 26086-26091.

Fischmeister, R. and H.C. Hartzell. 1986. Mechanism of action of acetylcholine on calcium current in single cells from frog ventricle. J. Gen. Physiol. 376: 183-202.

Galdzicki, Z., F. Lin, O. Moran, A. Novelli, G. Puia, and M. Scianlepore. 1991. Development of voltage-dependent ionic currents in rat cerebellar granule cells grown in primary culture. Int. J. Neurosci. 56: $193-200$.

Gao, W.-Q. and M.E. Hatten. 1993. Neuronal differentiation rescued by implantation of weaver granule cell precursors into wild-type cerebellar cortex. Science 260: 367-369.

Gao, W.-Q., X.L. Liu, and M.E. Hatten. 1992. The weaver gene encodes a nonautonomous signal for CNS neuronal differentiation. Cell 68: 841-854.

Goldowitz, D. 1989. The weaver granuloprival phenotype is due to intrinsic action of the mutant locus in granule cells: Evidence from homozyogus weaver chimeras. Neuron 2: 1565-1575.

Goldowitz, D. and R.J. Mullen. 1982. Granule cell as a site of action in the weaver mouse cerebellum: Evidence from heterozygous mutant chimeras. J. Neurosci. 2: 1474-1485.

Goldowitz, D. and R.J. Smeyne. 1995. Tune into the weaver channel. Nature Genet. 11: 107-109.

Gravel, C., N. Leclerc, J. Rafrafi, R. Sasseville, L. Thivierge, and R. Hawkes. 1987. Monoclonal antibodies reveal the global organization of the cerebellar cortex. J. Neurosci. Methods 21: 145-157.

Haws, C.M., P.A. Slesingerm and J.B. Lansman. 1993. Dihydropyridine and $\omega$-conotoxin-sensitive $\mathrm{Ca}^{2+}$ currents in cerebellar neurons: Persistent block of L-type channels by a pertussis toxin-sensitive G-protein. I. Neurosci. 13: 1148-1156.

Harrison, S.M.W. and S. Roffler-Tarlov. 1993. Histological analysis of the male-sterile phenotype seen in the neurological mouse mutant weaver. Soc. Neurosci. Abst. 19: 1690 .

Hoffman, C.S. and F. Winston. 1987. A ten minute DNA preparation from yeast efficiently releases autonomous plasmids for transformation of Escherichia coli. Gene 57: $267-272$.

Huettner, J.E. and R.W. Baughman. 1986. Primary culture of identified neurons from the visual cortex of postnatal rats. J. Neurosci. 6: 3044-3060.

Huston, E., G. Cullen, M.I. Sweeney, H. Pearson, M.S. Fazeli, and A.C. Dolphin. 1993. Pertussis toxin treatment increases glutamate release and dihydropyridine binding sites in cultured rat cerebellar granule neurons. Neurosci. 52: $787-798$.

Irving, N.G, M.P. Citron, and R.H. Reeves. 1993. The positions of twelve simple sequence repeat markers relative to reference markers on mouse Chromosome 16. Mamm. Genome 4: 364-367.

Jalonen, T., S. Johansson, I. Holopainen, S.S. Oja, and P. Arhem. 1990. Single-channel and whole-cell currents in rat cerebellar granule cells. Brain Res. 535: 33-38.

Kobayashi, T., K. Ikeda, T. Ichikawa, S. Abe, S. Togashi, and T. Kumanishi. 1995. Molecular cloning of a mouse $\mathrm{G}$ protein-activated $\mathrm{K}^{+}$channel (mGIRK1) and distinct distributions of three GIRK (GIRK1, 2 and 3) mRNAs in mouse brain. Biochem. Biophys. Res. Commun.

208: 1166-1173.

Krapivinsky, G., E.A. Gordon, K. Wickman, B. Velimirovic, L. Krapivinsky, and D.E. Clapham. 1995. The G-protein-gated atrial $\mathrm{K}^{+}$channel IK[ACh] is a heteromultimer of two inwardly rectifying $\mathrm{K}^{+}$-channel proteins. Nature 374: 135-141.

Kurachi, Y. 1995. G protein regulation of cardiac muscarinic potassium channel. Am. J. Physiol. 269: C821-C830.

Lambert, R.C. and A. Feltz. 1995. Maintained L-type $\mathrm{Ca}^{2}+$ channel activity in excised patches of PTX-treated granule cells of the cerebellum. J. Neurosci.

15: 6014-6022.

Lesage, F., F. Duprat, M. Fink, E. Guillemare, T. Coppola, M. Lazdunski, and J.-P. Hugnot. 1994. Cloning provides evidence for a family of inward rectifier and G-protein coupled $\mathrm{K}^{+}$channels in the brain. FEBS Lett. 353: $37-42$.

Marchetti, C., C. Carignani, and M. Robello. 1991. Voltage-dependent calcium currents in dissociated granule cells from rat cerebellum. Neurosci. 43: 121-133.

Mintz, I.M. and B.P. Bean. 1993. GABA B receptor inhibition of P-type $\mathrm{Ca}^{2+}$ channels in central neurons. Neuron 10: 889-898.

Mjaatvedt, A., M.P. Citron, and R.H. Reeves. 1993. High resolution mapping of D16Led1, Gart, Gas-4, Cbr, Pcp-4, and $\mathrm{Erg}$ on mouse Chromosome 16. Genomics 17: $382-386$

Nichols, C.G., J. Jerrer, W. Pearson, E. Makhina, and A. Permutt. 1995. M2 muscarinic receptor-activated $\mathrm{K}^{+}$currents in oocytes co-expressing GIRK1, GIRK2 and CIR cDNAs. J. Physiol. 487: 188.

O'Hara, B.F., C. Bendotti, R.H. Reeves, M.L. Oster-Granite, J.T. Coyle, and J.D. Gearhart. 1988. Genetic mapping and analysis of somatostatin expression in Snell dwarf mice. Mol. Brain Res. 4: $283-292$. 


\section{GIRk2 AS A wv CANDIDATE GENE}

O'Hara, B.F, S. Fisher, M.L. Oster-Granite, J.D. Gearhart, and R.H. Reeves. 1989. Developmental expression of the amyloid precursor protein, growth-associated protein 43 , and somatostatin in normal and trisomy 16 mice. Dev.

Brain Res. 49: 300-304.

Orita, M., H. Iwahana, H. Kanazawa, K. Hayashi, and T. Sekiya. 1989. Detection of polymorphisms of human DNA by gel electrophoresis as single-stand conformation polymorphisms. Proc. Natl. Acad. Sci. 86: 2766-2770.

Patil, N., D.R. Cox, D. Bhat, M. Faham, R.M. Myers, and A.S. Peterson. 1995. A potassium channel mutation in weaver mice implicates membrane excitability in granule cell differentiation. Nature Genet. 11: 126-129.

Pavan, W.J., P. Hieter, and R.H. Reeves. 1990. Generation of deletion derivatives by targeted transformation of human-derived yeast artificial chromosomes. Proc. Natl. Acad. Sci. 87: 1300-1304.

Peterson, A., N. Patil, C. Robbins, L. Wang, D.R. Cox, and R.M. Myers. 1994. A transcript map of the Down Syndrome critical region on Chromosome 21. Hum. Mol. Genet. 3: 1735-1742.

Rakic, P. and R.L. Sidman. 1973. Sequence of developmental abnormalities leading to granule cell deficit in cerebellar cortex of weaver mutant mice. $J$. Comp. Neurol. 152: 103-132.

Reeves, R.H., M.R. Crowley, N. Lorenzon, W.J. Pavan, R.J. Smeyne, and D. Goldowitz. 1989. The mouse neurological mutant weaver maps within the region of Chromosome 16 that is homologous to human Chromosome 21. Genomics 5: 522-526.

Reeves, R.H., M.R. Crowley, B.F. O'Hara, and J.D. Gearhart. 1990. Sex, strain, and species differences affect recombination across an evolutionarily conserved segment of mouse Chromosome 16. Genomics 8: $141-148$.

Reeves, R.H., M.R. Crowley, W.S. Moseley, and M.F. Seldin. 1991. Comparison of interspecific to intersubspecific backcrosses demonstrates species and sex differences in recombination frequency on mouse Chromosome 16. Mamm. Genome 1: 158-164.

Scherer, R.W. and G.E. Breitwieser. 1990. Arachidonic acid metabolites alter $G$ protein-mediated signal transduction in heart. J. Gen. Physiol. 96: 735-755.

Schmidt, M.J., B.D. Sawyer, K.W. Perry, R.W. Fuller, M.M Foreman, and B. Ghetti. 1982. Dopamine deficiency in the weaver mutant mouse. J. Neurosci. 2: 376-380.

Smeyne, R.J. and D. Goldowitz. 1989. Development and death of external granular layer cells in the weaver mouse cerebellum: a quantitative study. $J$. Neurochem. 9: $1608-1620$.

Tsaur, M.-L., S. Menzel, F.-P. Lai, R. Espinosa, P. Concannon, R.S. Spielman, C.L. Hanis, N.J. Cox, M.M.
LeBeau, M.S. German, L.Y. Jan, G.I. Bell, and M. Stoffel. 1995. Isolation of a cDNA clone encoding a $K_{\text {ATP }}$ channel-like protein expressed in insulin-secreting cells, localization of the human gene to chromosome band 21q22.1, and linkage studies with NIDDM. Diabetes 44: $592-596$.

Tseng, G.-N. and B.F. Hoffman. 1990. Actions of pinacidil on membrane currents in canine ventricular myocytes and their modulation by intracellular ATP and cAMP. Pfluegers Archiv. Eur. J Physiol. 415: 414-424.

Tung, L. and M. Morad. 1985. A comparative electrophysiological study of enzymatically isolated single cells and strips of frog ventricle. Pfluegers Archiv. Eur. J. Physiol. 405: 274-284.

Zegarra-Moran, O. and O. Moran. 1994. Properties of the transient potassium currents in cerebellar granule cells. Exp. Brain Res. 98: 298-304.

Received October 18, 1995; accepted in revised form November 27, 1995. 


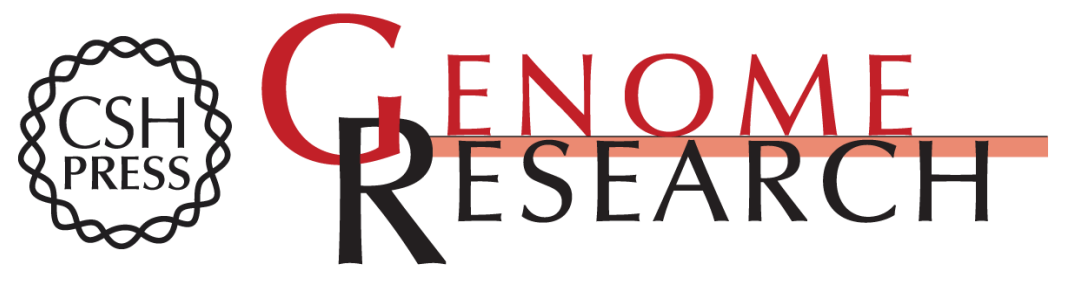

\section{Assessment of a mutation in the $\mathrm{H} 5$ domain of Girk2 as a candidate for the weaver mutation.}

A E Mjaatvedt, D E Cabin, S E Cole, et al.

Genome Res. 1995 5: 453-463

Access the most recent version at doi:10.1101/gr.5.5.453

References This article cites 46 articles, 13 of which can be accessed free at:

http://genome.cshlp.org/content/5/5/453.full.html\#ref-list-1

\section{License}

Email Alerting Receive free email alerts when new articles cite this article - sign up in the box at the Service top right corner of the article or click here.

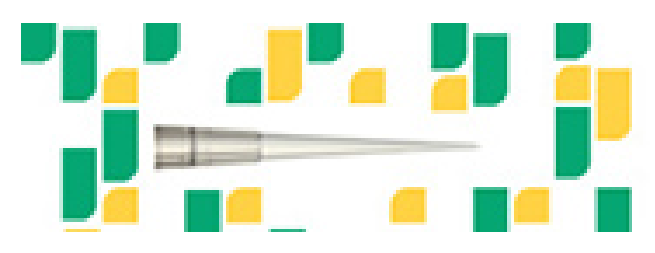

To subscribe to Genome Research go to: https://genome.cshlp.org/subscriptions 